\title{
Stable Disease Minimum Duration
}

National Cancer Institute

\section{Source}

National Cancer Institute. Stable Disease Minimum Duration. NCI Thesaurus. Code C98783.

The minimum amount of time required to meet the definition of stable disease. 